\title{
NARRATIVAS CINEMATOGRÁFICAS EN EL CONTEXTO DE DOS GUERRAS MUNDIALES. (LA CIENCIA POLÍTICA Y EL FILM DE LO COTIDIANO)"*
}

José Fernando Saldarriaga Montoya**

\section{RESUMEN}

"Narrativas cinematográficas en el contexto de dos guerras mundiales. (La ciencia política y el film de lo cotidiano)" Es la configuración de la ciencia política con relación al cine, estas se convierten en dos formas de interacción que permiten abordar hermenéuticamente como modelo de análisis las interpretaciones sobre la historia y la política, entre otros ejes analíticos de este ensayo. En consecuencia con lo anterior, la estructuración de una ciencia política y su relación con la estética cinematográfica, conlleva a construir un modelo de análisis que nos permite entender nuestro presente. En este capítulo se proyecta comprender cómo la narración estética del cine y la ciencia política delinearon no sólo el significado de lo cotidiano, sino que es la representación gramatical de las causas y las consecuencias de los acontecimientos historicos $y$ geopoliticos, como :el origen de la república de Weimar, El Tratado de Versales causas del surgimiento del Nazismo.

Palabra claves: Narrativas, interacción, poder, micropolítica, comunicación medial, estética, modernidad Weimar, Nazismo.

\section{SUMMARY}

"Film narrative in the context of two worldwide wars (Political science and daily life's film)" It is the configuration of political science in relation to the movies, these become two forms of interaction which allow one to hermeneutical analysis as a model of interpretations of history and politics, between other analytical axes of this essay. In consequen ce with this, the structuring of a political science and their relationship with film aesthetics, leads to build an analysis model that allows us understand our present. This chapter intends to understand how the aesthetics of film narrative and political science have delineated not only the meaning of the everyday, but it is the grammatical representation of the causes and consequences of historical and geopolitical events, such as: the origin of the Weimar Republic, the Treaty of Versailles and the causes of the rise of Nazism.

Keywords: Narrative, interaction, authority, micro politic, medial communication, aesthetics, modernity Weimar, Nazism.

Fecha de recepción: julio 5 de 2009

Fecha de aceptación: septiembre 3 de 2009

* Avance de la investigación Cine y Ciencia política, un modelo para armar.

** Sociólogo, Especialista en Análisis Político y del Estado. Universidad Autónoma Latinoamericana de Medellín, Unaula. Candidato a Magister en Ciencia Política y Relaciones Internacionales de la Universidad Pontificia Bolivariana de Medellín. Profesor de ( 


\section{INTRODUCCIÓN}

Este capítulo es un avance de investigación adscrito al Centro de Investigaciones Socio-jurídicas (CISJ) de la Facultad Derecho UNAULA, es la derivación de una trayectoria académica que tiene sus inicios en los procesos culturales $y$ académicos en los cineclubes, en la ciudad de Medellín y en particular en el municipio de Envigado, en el cual tuve la fortuna, junto con un grupo de amigos y amigas, de desarrollar programaciones en el Cine-Club Cine-Ojo, especialmente el cine facilitado por las embajadas: Alemana y Americana en las décadas de los años setenta, ochenta y noventa. Con el trascurso de los años se fue implementando esta experiencia en ambientes académicos, en particular en los programas curriculares, debates y conferencias programadas por centros culturales y diversas universidades de la ciudad. Es así que el presente ejercicio reflexivo es el fruto de diversas disertaciones entre estudiantes, profesores, colegas y amigos en el marco de la necesidad de establecer un vínculo interdisciplinario entre la Ciencia Política, Derecho "artesanía intelectual" en un posible modelo de análisis. Producto de lo anterior es la implementación en el plan de estudios de la Facultad de Derecho y la electiva Cine Derecho, literatura y política como una forma de comprender el derecho desde el discurso cinematográfico.

Se asistirá a unas aproximaciones históricas, para identificar los principales hechos que rodearon estas narraciones cinematográficas. Films como "Bajo los techos de París" (1930), René Clair, "El gabinete del doctor Caligari" (1920), de Robert Wiene, y "M, el vampiro de Düsseldorf" (1931), de Fritz Lang, que integran de forma consciente los significados de una sociedad que no siendo ajena, es ajena a las circunstancias políticas, representaron con sus producciones estéticas y en particular las preocupaciones propias de la época, los conceptos de interacción social y microfísica del poder, como marco de referencia de la ciencia política, serán el objeto de este análisis.

1. NARRATIVAS CINEMATOGRÁFICAS EN EL CONTEXTO DE DOS GUERRAS MUNDIALES. (LA CIENCIA POLÍTICA Y EL FILM DE LO

\section{COTIDIANO).}

La imagen visual muestra la estructura de una sociedad, su situación, sus lugares y sus funciones, las actitudes y los roles, las acciones y las reacciones de los individuos, en suma, la forma y sus contenidos.

Gilles Deleuze. La imagen-tiempo

Argumentar el cine como escenario de lo cotidiano es registrar sus propios orígenes. Para algunos historiadores del séptimo arte, el cinematógrafo inicia un proceso cuya denominación sería "cine primitt" pro cia; es un proceso de experimentación tecno-social. En este sentido, se dan los inaugurales caminos empíricos que enunciarán los primeros significados en imágenes de la vida cotidiana: calles, rostros, estilos de vestir, expresiones; para ser más precisos, formas de interacción social. Jean Mitry, en su libro "La estética y sicología del cine. 2 La forma" argumenta que todos los objetos y espacios en el cine se interaccionan y, por lo tanto, definen la imagen a través de la cual, y por la cual, se nos ofrece el mundo: Tomemos un rincón de las calles: una casa, el final de la acera un farol de gas, un hombre que camina. Evidentemente hay un conjunto de relaciones geométricas y geográficas (de lugar, de situación, de tamaño, de orientación, etc.) entre esas partes diversas. Pero no por ello están aisladas. Mantienen otras relaciones con las demás partes de la calle $y$ éstas con las calles vecinas (Mitry p. 4,1978)

La posibilidad que el cinematógrafo ofrece desde sus comienzos es, sin duda, el acceder de una forma innovadora a la representación de la vida moderna, en particular, a la vida cotidiana. Estos dos elementos, vida moderna y cotidianidad, fueron lo que tanto sedujo a las vanguardias estéticas de los primeros años del Siglo XX. En suma, el cine, desde el punto de vista sociológico y político, no es simplemente reproducciones de la sociedad, sino signos históricos y políticos que interactúan con el mundo social. En este sentido, el cine, como representación técnico-social, refleja las relaciones del ser humano con el tiempo, con el espacio y, sobre todo, con los aspectos socioculturales y políticos de los individuos y de los grupos sociales. En concordancia con esto, se puede indicar que el cine cuestiona la objetividad de la realidad, para delimitar lo social y lo político.

Por eso, al introducirnos en el campo de lo micropolítico, el cine se aproxima a unos conceptos, de tantos, que innovaron la sociología y la ciencia política del Siglo XIX, el interaccionismo, de Georg Simmel (1858-1918), en la medida en que la sociología simmeliana funda su teoría en la mirada en su conjunto. Según lo anterior, el cine concreta unidades establecidas que oscilan entre las formas sociales y las acciones recíprocas, es decir Cómo los individuos y los grupos se comportan entre ellos, cómo los individuos se comportan frente a su grupo [...] Pór lo tanto, la socialización es la forma que se realiza de incontables maneras diferentes en las que va creciendo la unión de los individuos en razón de aquellos intereses sensitivos o ideales, momentáneos o duraderos, conscientes o inconscientes, que empujan causalmente $o$ arrastran teleológicamente y que se realizan dentro de esta situación. (Simmel p. 4,2000$)$

La anterior definición de sociabilidad, que no es más repercusión recíproca de la interacción de los individuos, destaca los signos sociales conscientes o inconscientes que permiten que los hombres se comuniquen y construyan códigos comunes. "Estas repercusiones recíprocas significan que los portadores individuales de estos impulsos causantes y fines forman una unidad, o sea, una sociedad".

La comunicación medial que desarrolla la narrativa cinematográfica, desde este punto de vista, es una estructura social en permanente movimiento, y está compuesta de interacciones sociales que inscribe procesos simbólicos comunicativos no ajenos a la realidad política en la que se circunscriben. Las interacciones entre el cine y la microsociología están constituidas por discontinuidades de la cultura y sus acciones. Es cierto, la imagen de la pantalla está privada de cuerpo, un mero simulacro compuesto de luces y sombras. Y sin embargo, el espectador se ve inducido a atribuirle un cierto valor de realidad como si nada lo distinguiera de los cuerpos, los gestos vivos que la cámara ha registrado en un pasado más o menos lejano (Pezella, p 43, 2004):

Presentadas las anteriores disposiciones conceptuales, como la interacción social y la micropolítica, dos contenidos que establecen perspectivas de interés para comprender la producción de imágenes en la sociedad moderna de principio de siglo, y sus conflictos, se entrará a delimitar en las películas anteriormente señaladas, y su estrecha relación con la estética cinematográfica y la ciencia política.

1.1 Signo y poder político: "El gabinete del doctor Caligari" (1919-20), de Robert Wiene

Somos criaturas del tiempo y no creadores de éste y nuestra razón es el juguete de la Razón y no su principio que domina. Durante la crisis, nuestro entendimiento está condicionado por el conflicto $y$ encadenado a un lado u otro en la lucha de las ideologías.

R. H. S. Crossman. Biografía del Estado Moderno

En el contexto de la Primera Guerra Mundial (19141920), un grupo de académicos alemanes, motivados desde el Romanticismo alemán del Siglo XIX, en particular desde la literatura y la arquitectura, $y$ críticos de los vientos del progreso y la política, suscribieron un movimiento cinematográfico que se denominó Expresionismo alemán. Para algunos historiadores del cine, nació con el film "El Gabinete del doctor Caligari". Es la Alemania de los años veinte, introducida en un gran malestar sociopolítico, marcada por la inflación económica, por el desempleo y, en general, por un enorme desencanto cultural.

De esta manera, "El gabinete del doctor Caligari", es el esplendor del Expresionismo alemán que, como percepción estética, reivindica la frialdad de una sociedad que se asoma al descanto de un modelo político que siente su primer trance; una sociedad que marcha políticamente hacia la dominación de 
las conciencias colectivas y al crecimiento del mundo técnico, que, en coherencia con los posmoder-
nos, se podría denominar como la primera crisis del humanismo; el crecimiento de la racionalidad instrumental y la sociedad tecnificada: "El mundo se ha vuelto tan "permeable" que, en todo momento, parece que surgen a la vez el espíritu, la visión y los fantasmas" (Eisner, p. 20, 1988) Caligari es la representación de una sociedad que se dirige hacia la dominación individual y la maquinización de la sociedad, como consecuencia del inicio del oscurantismo político. En Caligari, la interpretación expresionista ha conseguido con raro éxito evocar la 'fisonomía latente' de una pequeña ciudad medieval de callejuelas tortuosas y sombrías, pasadizos estrechos con casas desmoronadas cuyas fachadas, inclinadas, no dejan nunca pasar la luz del día. Las puertas se convierten en bocas abiertas y en gargantas tas se convierten en bocas abiertas y en capaces de arrojar llamadas estridentes (Eisner, pp. 28-30)

"Caligari" es la expresión de una modernidad en crisis, simbolizada en imágenes y sombras que serían la representación sígnica de lo político: el control social. La decoración, los telones oscuros, líneas de sesgos, expresiones vampiresas, control del tiempo, la disolución del ser en el valor de cambio, sociedades panópticas son, tal vez, la expresión estética y política de un proyecto moderno que todavía, a principios del Siglo XX, encuentra mucha oscuridad. "Los historiadores de las ideas atribuyen fácilmente a los filósofos y a los juristas del Siglo XVIII el sueño de una sociedad perfecta; pero ha habido, también, un sueño militar de la sociedad; su referencia fundamental se halla no en el estado de naturaleza, sino en los engranajes cuidadosamente subordinados de una máquina, no en el contrato primitivo, sino en las coerciones permanentes, no en los derechos fundamentales, 5 chos fundamentales, sino en la educación y formación indefinidamente progresivos, no en la voluntad general, sino en la docilidad automática. (Foucault p. 173. 2002)

La estructura cinematográfica del film "El gabinete del doctor Caligari" muestra en sus decorados una idea de calabozo, que lleva a pensar que cada obje- to es colocado en la narrativa cinematográfica como una crítica enfática a la racionalización de la vida individual y colectiva. De igual manera, el mismo término gabinete representa las futuras formas que realizó el fascismo para el exterminio de los judíos: las cámaras de gas y los ghetos, entre otros. "El misterioso doctor Caligari, que no tiene ni sombra de escrúpulo humano, actúa con una insensibilidad loca, con ese desafío a la moral corriente que los expresionistas exaltan". Para Lotte H Eisner, "Los decorados de Caligari han conseguido dar la idea del calabozo en lo absoluto".

Caligari es un viejo y legendario médico que aparece, de repente, en una feria circense al norte de Alemania, en un pueblo llamado Holstenwall. Él quiere mostrar su fenómeno: un hombre que ha estado muerto durante mucho tiempo y el doctor, bajo el efecto de la magia, lo resucita. Pero este personaje es un asesino nocturno que rompe con la armonía de una fiesta. Una fiesta moderna, llena de asombro y optimismo.

Caligari, gran dominador de su espectáculo, atraviesa todos los espacios. Espacios oscuros, decorados oblicuos, calles que parecen laberintos. Los decorados están distorsionados, representados en maquetas o cartones pintados, superpuestos para crear ilusiones; lo urbano es representado de forma analógica con decorados expresivos que establecen una interacción con los actores. Callejones sin salida, que terminan en un punto oscuro, en donde la incertidumbre permanece. Nada está claro, nadie sabe lo que pasa, pero lo que sí es cierto es que anda la muerte por los rincones de los decorados expresionistas, que es la ciudad misma.

La modernidad, como en la película, se inicia en un punto y nadie sabe en dónde termina. En Caligari, la modernidad es una fiesta líquida, en donde se destacan sombras oscuras y contrastes urbanos, allí nada permanece $y$ todo es movimiento. Ha llegado el yo absoluto que domina con el misterio $y$ la incertidumbre, nadie quiere ser víctima. Caligari es contrario al movimiento, desea que todo esté en sus manos. Asoma su rostro, para proclamar el individualismo totalitario y la dominación de las colectividades.

Caligari es, entonces, lo análogo a la modernidad: "los objetos de la realidad se han tornado unidades de imagen, al mismo tiempo que la imagen-movimiento pasó a ser una realidad que habla a través de sus objetos (Deleuze, p46. 1987). Cada detalle de la película está inscrito en la misma preocupación modernista, la racionalidad instrumental: "El arte por sí mismo, ha de volverse contra su propio principio, y transformase en rebelión contra la apariencia estética" (Wellme, p. 22 .1993). Por eso, este film no es sólo una casualidad, es también una posición política a través de los objetos-signos.

1.2 "Todo lo sólido se desvanece en el cine: "M, el vampiro de Düsseldorf" (1931), Fritz Lang, y "Bajo los techos de París" (1931), de René Clair: de lo macro a lo micro de la interacción en el cine.

- De lo macro a lo micro de la interacción. Los procesos que desarrolló la modernidad en el contexto de la ciudad y la política en el Siglo XIX, están articulados a las gramáticas visuales que, en términos estéticos, ha desarrollado el cine desde sus inicios. Sin duda, el cine está compuesto de lo urbano. Escribe Manuel Delgado Ruiz que "El cine y lo urbano están hechos, al fin y al cabo, de lo mismo: una estimulación sensorial ininterrumpida hecha de secuencias de acción, excitaciones imprevistas, impresiones inesperadas. En la calle, como en las películas, siempre pasan cosas. (Delgado,p. 58, 1999).

Con este argumento, se podría establecer una estrecha relación entre el cine y la microsociología. Este concepto, cuyos orígenes se encuentran en la escuela del interaccionismo simbólico, define tres dimensiones sociológicas: la primera, establece el análisis de la interacción entre el sujeto y el mundo. Los sujetos sociales establecen una relación con el mundo y le dan un significado. La segunda, la concepción del sujeto y del mundo, es decir, la movilidad interpretativa del mundo de las cosas como procesos dinámicos y no como estructuras estáticas. Y la tercera, la significativa importancia asignada a la capacidad del sujeto para interpretar y racionalizar el mundo social. Estos tres elementos los capta la cámara que, a diferencia de la mirada, selecciona espacios $y$ acontecimientos, construyendo imágenes en argumentos; en otras palabras, es la observación cinematográfica. El cine capta lo fugaz y lo fragmentario de la realidad, cada uno de los detalles de la realidad, la imagen instantánea de la interacción social, todas las formas minimalistas de la sociedad que la sociología formal no está en condiciones de captar y mucho menos de analizar". (Delgado, p. 6. 1999). En suma, las sociedades establecen relaciones con el medio y producen sentido. Tal producción de sentido se relaciona con todas las dimensiones de la vida, en particular con los sistemas micro-sociales, como por ejemplo, las costumbres, las conductas, el comportamiento, el razonamiento y las percepciones que comprenden todos los procesos implicados en la vida cotidiana. Gilles Deleuze precisa que: "El cine mudo no cesa de mostrar la civilización, la ciudad, el apartamento, los objetos de uso, de arte o de culto, todos los artefactos posibles. Sin embargo, les comunica una suerte de naturalidad que es como el secreto y la belleza de la imagen muda [...] La imagen visual muestra la estructura de una sociedad, su situación, sus lugares y sus funciones, las actitudes y los roles, las acciones y reacciones de los individuos; en suma, la forma y los contenidos (Deleuze p298).

El cine descifra lo urbano desde la heterogeneidad del signo social y de lo político, es un sistema microsocial en el cual las interacciones se mezclan íntimamente con las estructuras sociales, así constituyen toda una puesta en escena, una dramaturgia de la vida cotidiana: como desasosiegos, simulaciones y laberintos, en los que se expone un campo de percepción y de visibilidad estética a través de los acontecimientos cotidianos. En otras palabras, lo que Charles Fourier, en el Siglo XIX, denomina procesos de sujetivación en la vida cotidiana. Al respecto, Édgar Garavito dice que "para Fourier hay una aproximación que se está viviendo cada vez más hoy entre política, ética y estética, y para él lo más importante era, ciertamente, la estética de las pasiones, como se producen en el espacio y el tiempo". (Garavito, 1997) 
De la misma manera, el cine construye el relato social como parte de lo urbano: el rumor, la conversación, el caminar en la ciudad, los maleantes, el aventurero, el amor, es decir, cómo se habita la ciudad. Es un proceso de interacción entre el sujeto y el espacio que, en términos del sociólogo alemán George Simmel, es un entramado de sistemas sociales, relacionados con imágenes, miradas, formas de actuar, la circulación libre de las pasiones; espacio e interacciones cotidianas sobre los cuales reflexiona como procedimientos de experimentación y sujetivación. Son formas de percepción estimuladas por el moderno entorno urbano: "La sociología de Simmel se funda en la idea de que la naturaleza de la existencia social está gobernada por los individuos en tanto actores-protagonistas de la acción-, en los que cada papel o rol se revela no sólo por la imagen del otro sino también por el conocimiento del contexto (Delgado, p.7).

Teniendo en cuenta las disertaciones anteriores, se constituirá un análisis desde los films " $M$, el vampiro de Dusseldorf" y "Bajo los techos de París", para comprender cómo los mecanismos micro-político y microsociales coexisten con la estructura social e individual.

1.2.1 "M, el vampiro de Düsseldorf" o "Los asesinos están entre nosotros"*. Un mapa micropolítico

La delincuencia es un instrumento para administra vexplotar los ilegalismos.

Michel Foucault. Vigilar y Castigar

El expresionismo, como vanguardia estética y política, fue notablemente audaz, develó -como se argumentó en el acápite del film "El gabinete del doctor Caligari" - los muros oscuros de la modernidad política, en particular la razón Estado, el Estado policía. * Titulo original de la pelicula, censurado por los fascistas. Estratégicamente,
Lang le asigna el nombre de "M, el vampiro de Düsseldorf".

46 / Revista Facultad de Derecho. Ratio Juris Vol. 4 No. 9 (2009)
Con un plano-secuencia, - de arriba hacia abajoel film comienza con una ronda infantil que alude en su canto a la llegada de un asesino que acabaría con las vidas de todos los habitantes. La cámara entra en la ciudad y sus personajes, y le da un significado al entramado urbano para dar inicio al código del suspenso. De repente, la pequeña Elsie Beckmann se ve seducida por un extraño a la salida del colegio. Ella será la próxima víctima de un asesino de ciudad que tiene consternados no sólo a los habitantes sino a todo el aparato administrativo. Se organiza todo un dispositivo de poder para dar captura al asesino, que nadie conoce pero creen identificar. La ciudad cae en la más profunda paranoia colectiva en la que se ve el asesino en todas partes. Estado y hampa coinciden en hacer justicia proponiendo una red de soplones para acorralar al asesino con el objetivo de eliminarlo. La doble moral se apodera de una sociedad que se cree con derecho a destruir a aquel que ha modificado el orden, pero la historia del asesino, que asusta a la ciudad, no es más que la develación de un Estado y una sociedad desencantados, preparada para la dictadura: "Ninguna película supo poner en evidencia mejor que "M. El vampiro de Dusseldorf" el peso del destino que abruma al individuo, destino por el pulpo social en toda su arrogancia (Beyle, p. 94, 2006). En el film, el mensaje político es claro: el miedo nos hace dóciles para la conciencia individual y colectiva. Este es uno de los significados más contundentes de este film político. Así lo indicó Michel Foucault (Foucautl p.37, 2004) cuando argumenta que el Estado moderno necesita producir "el extraño" para justificar su acción policiva o jurídica, y, en consecuencia, diseñar un saber-poder: La apuesta de todas esas empresas acerca de la locura, la enfermedad, la delincuencia, la sexualidad y el tema del que les hablo hoy es mostrar que el acoplamiento serie de prácticas- regímenes de verdad forma un dispositivo de saber-poder que marca efectivamente en lo real inexistente, y lo somete en una forma legítima a la división lo verdadero de lo falso (Foucautl p37, 2004).

En el contexto del anterior razonamiento, dos características se destacan en este film. La primera, Lang se divorcia del lenguaje alegórico y expresivo que caracterizó al cine expresionista. Es directo y pone en evidencia desde un contexto micropolítico las intenciones pasionales e irracionales de una sociedad y un Estado moderno que "creaba el orden a golpe de legislación y que lo definía con nitidez de las divisiones, clasificaciones, distribuciones y límites obligatorios y esta relación dual Estado-individuo desata lo que Deleuze y Guatari denominaron en el libro "Rizoma" los microfascismos grupales e individuales en donde, "los grupos y los individuos contienen microfascismos que sólo esperan para cristalizar". (Deleuze y Guatari P. 26).

Y la segunda, históricamente Alemania, en este período, es aislada del contexto internacional y no hace parte de tratado de Versalles por ser un país vencido en el contexto de la Primera Guerra Mundial. R.H.S. Crosman lo define como un momento histórico estipulado entre 1918 y 1933, el cual "no fue el período del derecho internacional y el orden, sino el de la supremacía de las potencias vencedoras en Versalles (Crosman p. 239, 1994). Por lo tanto, es un momento importante para dar apertura a uno de los períodos más inexcusables de la historia occidental, en el contexto de lo que Crosmman denominó como el mito de la seguridad colectiva, es decir, fortalecimiento del nacionalismo como forma de gobierno. En otras palabras, es el inicio de la personificación de una nueva idea de Alemania, grande, representada en Adolfo Hitler, cuyo objetivo sería la estructuración del nacional-socialismo y del Tercer Riech.

Como consecuencia de lo anterior, se estructuraría el Estado como forma de control sobre todas las esferas sociales e individuales. En suma, es la iniciación del modelo nacionalista denominado nazismo. Este es el contexto histórico y sociopolítico en donde aparece el film " $M$, el Vampiro de Düsseldorf". Sin duda alguna, es un diagnóstico micropolítico de una sociedad vigilada por el miedo y la eliminación del "extraño". En la sociedad moderna y bajo la tutela del Estado Moderno, la aniquilación cultural y/o física de los extraños y de lo extraño consistía en una destrucción creativa; derribar pero al mismo tiempo construir; mutilar pero también enderezar, se trataba de una tarea esencial del esfuerzo en curso de construcción del orden (Bauman P.29, 2000)

Pero además, la película es una denuncia indiscutible de las estructuras sociales y políticas, estructuras cuyo objetivo es la destrucción de toda posibilidad de justicia racional. Es el argumento de lo que más tarde Michel Foucault, en su libro "Vigilar y castigar" denomina una micropolítica. Ahora bien, el estudio de esta micropolítica supone que el poder que en ella se ejerce no se conciba como una propiedad, sino como una estrategia, que sus efectos de denominación no sean atribuidos a una "apropiación", sino a unas disposiciones, a unas maniobras, a unas tácticas, a unas técnicas, a unos funcionamientos; que se descifre en él una red de relaciones siempre tensas [...]Este poder, por otra parte, no se aplica pura y simplemente como una obligación o una prohibición a quienes "no lo tienen"; los invade, pasa por ellos y a través de ellos; se apoya sobre ellos. (Foucautl pp33-34):

1.2.2 "Bajo los techos de París" (1931), de René Clair (1898-1981). Lo micro de la interacción.

El mundo posmoderno se prepara para soportar una vida

bajo un estado de incertidumbre que es

permanentemente irreducible.

Zygmunt Bauman. La posmodernidad y sus descontentos.

"Bajo los techos de París" se realiza en los contextos de un nuevo orden estratégico en términos geopolíticos. Lo primero es la crisis social generada por el capitalismo en 1929. Y lo segundo, la estrategia utilizada por Alemania en cabeza de Adolfo Hitler para tomar liderazgo y desactivar el tratado de Versalles. De esta manera, el film es una puesta en escena de un momento histórico que padecen Francia y casi toda Europa, un verdadero período de incertidumbre. Crossman lo analiza con precisión histórica. El resurgimiento de Alemania como una fuerza militar en Europa, acabó con la difícil hegemonía que venían ejerciendo Francia y Gran Bretaña, y reintrodujo la política del equilibrio de poderes. De 1935 en 
adelante, las naciones más pequeñas tuvieron que elegir en cuál de los bloques contrarios iban a encontrar quién protegiera su independencia. En esta Hitler adoptó la misma técnica pleado para logar el poder en Alemania, es decir, se presentó ante el mundo como un protector de Europa contra el bolcheviquismo y así obtener la aten ción favorable de determinados grupos, que tanto en Inglaterra como en Francia son muy susceptibles I mito del terror comunista [...]. (Crossman, p.127)

René Clair, de forma magistral retrata en sus personajes las incertidumbres urbanas en una atmósfera microsocial, fotografía la crisis de la modernidad social y política fundada entre el Siglo XIX y los comienzos del Siglo XX. Como si fuera un acto omnicomprensivo, la cámara empieza a significar lo urbano, la ciudad aparece como la forma por la cual los individuos empiezan a interactua para ahondar en sus contenidos. Los tejados, los balcones, las puertas, la calles, los cuarto de hotel, los pasadizos oscuros, toman significado en la medida en que los individuos actúan sobre ellos. El film narra la historia de un tejido amoroso entre emigrantes bohemios, los artistas y los extranjeros. Albert, un cantante callejero, se ingenia la forma de sobrevivir, mientras tanto su amigo, un ladrón, hombre del hampa, aprovecha para robar la cartera a los distraídos. Pero Albert, que se ha enamorado de Pola, una inmigrante polaca, será también víctima de la estrategia, de igual manera, Fred, líder de una banda de gángsters, tiene intenciones sobre Pola. A Albert lo encarcelan por un robo que no ha cometido.

El film muestra una cartografía humana de la incertidumbre; no hay Estado, no hay quien responda por las malas acciones de los ciudadanos; por lo tanto, estas acciones se legitiman en el interior de significado urbano. Como el film " $M$, el Vampiro de Düseldorf" las acciones de justicia son tomadas por los mismos habitantes, pero se le agrega un factor social y político determinante: la relación inclusión-exclusión; los excluidos habitan los hoteluchos de mala muerte, y en las habitaciones de las casas, los inmigrantes y los pobres. Abajo los incluidos, los que habitan la ciudad funcional. En las noches, los de arriba bajan hacia el interior de las calles para hacer su cometido colectivo: la interacción. Al respecto Manuel Delgado se hace la siguiente pregunta: ¿Qué es lo que se mostraba en todas estas películas etnográficas a las que se está aludiendo? La respuesta es: interacción. Interrelaciones de seres humanos entre sí, con su medio ambiente social y natural, en cualquier caso, siempre con la cámara: son una sociedad, $o$, si se prefiere, un entramado de sistemas sociales (Delgado, $p$ 65).

"Bajo los techos de París" establece dimensiones espaciales y acciones recíprocas; por lo tanto, formas de socialización. La socialización y las acciones tienen la misma extensión: experiencia social y comunicativa. Por ejemplo, entre los gestos del cinemudo, visualizadas en los diálogos en el interio del bar, y en cine-parlante, los pasadizos de la calle tienen la connotación de la interacción y de la comunicación. Es un juego visual urbano: el secreto y la acción. Clair establece la derivación del adentro vel afuera, el no-lugar. Aśl lo expresa Manuel Delgado: El esquema de la calle, de la naturaleza puramente diagramática de lo que sucede en el espacio público, puede asimilarlo a la noción de no lugar, tal como la ha perfilado hermosamente Michel de Certau. Ámbito constituido por la acción innumerable nderminada, en apariencia insensata, de productores mal conocidos, poetas de asuntos, inventores de senderos en las junglas de la racionalidad funcionalista, ajenos a las marcas de los territorio prefabricados por lo que desplazan: los transeúntes imprevisibles, los peatones elaboran, entre el lugar del que parten y el lugar al que habrán de llegar, esos no-lugares, por lo que se escucha susurrar e murmullo de la sociedad, rumor infinito que produce el caminar de los antihéroes anónimos que van y que vienen, que circulan desbordándose o derivados por los relieves que les son impuestos. (Delgado, p.13).

De igual forma, el cine profundiza la crisis de la De igual forma, el cine profundiza la crisis de la en ella habitan otros discursos y representaciones "anómicas" de narrar la ciudad. La ciudad, en este film, es una complejidad comunicativa de acciones recíprocas, por lo demás una serie de relaciones sociales que siempre están en continuo comienzo. En este sentido, utilizando la percepción literaria que esboza el semiólogo Jorge Echavarría Carvajal, la ciudad toma sentido en el contexto de sus expresiones: Darán cabida a mendigos y profetas del Apocalipsis siempre aplazados, a prostitutas y matones a sueldo, a detectives de pacotilla, a adúlteros culposos, gatos que toman whisky y comentan la vida con notas de Jazz como fondo, a cinemas derruidos y pornófilos artríticos, a mafiosos y periodistas alcohólicos e impotentes... en fin, una galería que ahora parece querer contarnos la ciudad insomne en claves antes imposibles en nuestra narrativa. (Echavaría. 1999).

\section{A MODO DE CONCLUSIÓN}

En el cine, como en el análisis que se podría establecer desde la ciencia política, se denotan espacios cotidianos y escenarios y discursos de poder, interacciones, relaciones recíprocas, pero además objetos, formas de vestir, serían una serie de situaciones cotidianas que sin duda alguna están unidas a un sistema social cuyos significados representan un momento histórico determinado.

El cine y la ciencia política y derecho, coinciden en que las interacciones sociedad-individuo se entre- cruzan, constituyendo relaciones de comunicación de poder, consensos entre otros que, como consecuencia, urbanizan representaciones políticas. En este trabajo los argumentos lo sustentan las interacciones sociales y los micro -poderes que "podrían entenderse como producidas por las acciones y por las reacciones intercambiadas entre las conciencias elementales de que está constituida la sociedad". (Urmeneta, p. 2007) En suma, la interacción entre el cine y la ciencia política y el derecho, por análogas vías teóricas y estéticas, coinciden en determinar que si bien la sociedad es producto de una serie de representaciones y acciones colectivas y políticas, se puede catalogar como objetos de estudio en donde el cine, como método empírico y hermenéutico, es también un sistema gramatical que ayuda a develar los poderes ocultos de los sistemas autoritarios, entre otros. Héctor Freire investigador entre el cine y la ciencia política, dice: el cine político proporciona un modelo de reflexión a la vez estético e ideológico que explica en parte el éxito o la resonancia pública. Lo esencialmente político del cine será aquello que conmueva las certezas construidas a lo largo de la historia: una eficaz denuncia contra el proceso de institucionalización de las representaciones" (...) elaborar un "contrapoder" simbólico - discursivo en relación con el orden establecido del poder y con el discurso reprimido de los deseos colectivos. 
REFERENCIAS BIBLIOGRÁFICAS

Bauman, Żymunt. (2007) Amor líquido. Acerca de la fragilidad de los vínculos humanos México: Fondo de Cultura Económica. $201 \mathrm{p}$.

(2006) Modernidad líquida. México: Fondo de Cultura Económica.

(2001) La posmodernidad y sus descontentos. Madrid: Akal ediciones. 256 p.

Beylie, Claude. (2006) Películas claves de la historia del cine. Barcelona: Borealia Asesores.

Crossman, Richard Howard. (1994) Biografia del Estado moderno. México: Fondo de cultura económica, $351 \mathrm{p}$.

De Baecque, Antoine (Comp.). (2003) Política de los autores. Manifiesto de una generación de cinéfilos. Barcelona: Paidós Comunicación 145 cine. Pequeña antología de Cahier du Cinema 1. 178 p.

Delgado Ruiz, Manuel. El animal público. Barcelona: Anagrama.

La ciudad Líquida, Ciudad interrumpida. Medellín: Universidad Nacional de Medellín.

Dilthey, Wilhelm. Dos escritos sobre hermenéutica. El surgimiento de la hermenéutica y los esbozos para una crítica de la razón histórica. Bracelona. Agora de ideas, 247 p.

Deleuze, Gilles. (1984). Estudios sobre La imagen-movimiento cine 1. Barcelona: Paidós comunicación, $318 \mathrm{p}$.

. La imagen-tiempo. Estudios sobre cine 2. (1984) Barcelona: Paidós comunicación. 391 p.

Medellín, p.7.

La inmanencia: una vida. (1996) En: Revista Sociología. No 19, Universidad Autónoma Latinoamericana de

Echavarría Carvajal, Jorge. (1999) Narrar la ciudad hoy: Las otras elecciones. En: Revista Sociología No 22, Universidad Autónoma Latinoamericana de Medellín, (Septiembre, 1999).

Eisner, Lotte H .La pantalla demoníaca. (1988) Madrid: Cátedra Signo e Imagen.

Foucault, Michel. (1994) Un diálogo sobre el poder. Barcelona: Altaya. 163 p.

(2007) Nacimiento de la biopolítica. Buenos Aires: Fondo de Cultura Económica. $401 \mathrm{p}$.

(2004) Vigilar y castigar. Buenos Aires: Siglo Veintiuno Editores. $314 \mathrm{p}$.

Freire, Héctor. Cine político: la reivindicación de la política. Available from Internet: www.utopia.com.ar/artículos/memoria-freire.htm

Garavito, Édgar. (1999) ¿En qué se reconoce una micropolítica? En: Revista Sociología No 22, Universidad Autónoma Latinoamericana de Medellín, (septiembre, 1999), p. 103.

Harto de Vera, Fernando. (1995) Ciencia política y teoría política contemporánea: Una relación problemática. Madrid: Trotta.

Huici Urmeneta, Vicente. (2007) Espacio, tiempo y sociedad. Variaciones sobre Durkheim, Halbwachs, Gurvitch, Foucault y Bourdieu. Madrid: Akal.

Freire, Héctor. Cine político: la reivindicación de la política. Available from Internet: <URL: www.utopia.com.ar/artículos/memoria-freire.htm>

Metz, Christian. (2002) Ensayos sobre la significación en el cine. Barcelona: Paidós.

Mitry, Jean. La estética y sicología del cine.2 Las formas. (1978) España: Siglo veintiuno editores.

Pezzella, Mario. (2004) La estética del cine. Madrid: La bolsa de la medusa.

Rizo, Harold José. (2004) Evolución histórica del pensamiento político y económico. Cali: Universidad Autónoma de Occidente, $429 \mathrm{p}$

Romaguera, Joaquín. (1998) Textos y manifiestos del cine. Madrid: Cátedra. Signo e Imagen, 579 p.
Rosenstone Robert. (1997) Pasado en imágenes. El desafio del cine a nuestra idea de la historia. Barcelona: Ariel historia, $186 \mathrm{p}$.

Sorlin, Pierre. (1985) Sociologia del cine. México: Fondo de Cultura Económica, 264 p.

Trenzado Romero, Manuel. El cine desde la perspectiva de la ciencia política, España. Editorial Reis Universidad de Granada.

Vallespin, Fernando. (1999) (Ed.). Historia de la teoría política, Vol. Los fascismos Rafael del Águila. Madrid: Alianza. $369 \mathrm{p}$.

Wellmer, Albrecht. (1993) Sobre la dialéctica de la modernidad y posmodernidad. Crítica de la razón después de Adorno. Barcelona: Visor.

(.Freire www.utopia.com.ar/artículos/memoria-freire.htm P) 